\title{
An assessment of Adjustment Neuroticism among Cardiac patients
}

\author{
Dr. Thiyam Kiran Singh*, Roderick Monteiro**
}

\section{ABSTRACT:}

A heart-disease is a lifelong sickness, an irreversible condition that patients have to endure for life. The present study aims at assessing the adjustment-neuroticism of cardiac patients. A total sample of 60 out of which 33 chronic and 27 acute onset cardiac illness were collected from Vintage Hospital, Goa using Personal Data-Sheet and Adjustment-Neuroticism Dimensional Inventory. The result found chronic onset of their cardiac illness have more overall maladjustment when compare with acute cardiac illness and as well as most of the domains of adjustment namely ; Self Esteem - Self Inferiority, Nauturality - Obsessiveness, Independence Dependence and Innocence - Guilt except calmness and anxiety. So it can be concluded from this study that chronic onsets of cardiac illness have more maladjustment when compare with acute onset of cardiac illness.

Keywords: Assessment, Adjustment, Neuroticism, Cardiac Patients

\section{INTRODUCTION}

Adjustment is defined as a relationship between the individual and his environment, and this relationship is learnt through experience, so adjustment is a form of learning. Adjustment is a process by which a living organism maintains a balance between its needs and circumstances that influence the satisfaction of those needs. An individual not only adapts biologically to different kind of physical demands and pressures but also needs to adjust psychologically and emotionally as he has to live and lead life in interdependence with other individuals throughout life. Neuroticism is a tendency to experience negative emotions easily such as anger, depression, anxiety or vulnerability. It is sometimes called emotional instability. Personalities of this type are characterized by self-centrism anxiety and avoidance. The purpose of the study is to find out whether there is any maladjustment to the chronic cardiac illness patients so as to help them by providing a good environment, better coping techniques with stressors and also acknowledging them how to prevent from further worsening. A study was conducted by MeKonnen, (2011) investigate whether cardiovascular disease is related to certain personality factors in AfricanAmerican men. The result revealed that neuroticism was a better predictor of later in life development of cardiovascular disease than agreeableness.

*Assistant Professor and Clinical Psychologist, Dept. of Psychology, AIBAS, Amity University Rajasthan, Jaipur.

**M.Phil: Clinical Psychology trainee, Dept. of Psychology, AIBAS, Amity University Rajasthan, Jaipur.

(C) 2014 K Singh, R Monteiro; licensee IJIP. This is an Open Access Research distributed under the terms of the Creative Commons Attribution License (http://creativecommons.org/licenses/by/2.0), which permits unrestricted use, distribution, and reproduction in any Medium, provided the original work is properly cited. 
Promote positive social change by supporting clinicians, policy makers, researchers and the general public in understanding the role of personality factors (e.g., neuroticism) may play in interventions that can prevent cardiovascular disease.

\section{METHODOLOGY}

\section{Objectives:}

To study the pattern of adjustment-neuroticism and its dimensions among cardiac patients based on the onset of the cardiac disease (acute or chronic onset).

\section{Sample size:}

The population for the research comprised of 60 cardiac male and female between the ages of 35 years -75 years.

\section{Inclusion Criteria:}

1. Patients suffering from chronic and acute heart illness or cardiac illness.

2. Cardiac patients with a minimum amount of formal education (primary education) were chosen as a part of the study.

3. Cardiac patients familiar with the English language were included as a part of the study.

4. Male and Female cardiac patients between the ages of 35 years - 75 years were chosen which were inclusive of males and females.

\section{Exclusion Criteria:}

1. Patients who are not suffering from cardiac illness.

2. Those who cannot give their consent for study.

3. Those that is illiterate.

\section{Tools used for data collection:}

\section{Personal Data Sheet}

The personal data sheet was used to obtain relevant demographic and psycho-medico information of the sample.

2. The Adjustment Neuroticism Dimension Inventory (ANDI) of Singh and Bhargava (1999) measures seven dimensions of adjustment neuroticism through 105 questions which are presented in a mixed way. Retesting reliability coefficients have been ascertained for total score and scores in each primary dimension were as follows: Self esteem - Self inferiority (0.74), Happiness - Depression(0.78), Calmness - Anxiety (0.65), Naturality - Obsessiveness (0.83), Independence - Dependence (0.89), Feelings of being healthy - Hypochondriasis (0.68), 
Innocence - Guilt feelings (0.73) and Total ANDI (0.79). Retesting was done after an interval of three weeks - their values (.65 to .89) are quite satisfactory. To ensure construct validity of the test, the questions have been selected from research supported by Eysenck and Wilson (1975). To establish internal validity questions have been selected on the basis of their power of discrimination. Their values are quite satisfactory (.30 to .70). To ascertain predictive validity, persons belonging to lowest (sten score 1 and 2) and highest groups (sten score 9 and 10) were interviewed and observed.

\section{Procedure:}

A sample of 60 cardiac patients, both males and females were included in the study. Information was gathered about cardiac patients using personal data sheet and Adjustment Neuroticism Dimensional Inventory (ANDI). All the questionnaires were distributed among the cardiac patients who fulfilled the inclusion criteria. While giving out the questionnaires, brief and concise information about the research and the purpose of the study was communicated to the participants.

\section{STATISTICAL ANALYSIS}

Percentage mapping was used to draw a pattern of Adjustment - Neuroticism among the sample.

\section{RESULTS:}

Table: Indicating percentages for Adjustment - Neuroticism and its dimensions based on Onset.

\begin{tabular}{|c|c|c|c|c|}
\hline $\begin{array}{lcc}\text { A-N } & \& & \text { ITS } \\
\text { DIMENSIONS } & \end{array}$ & ONSET & $\begin{array}{l}\text { Well- } \\
\text { Adjustment }\end{array}$ & $\begin{array}{l}\text { Normal } \\
\text { Status }\end{array}$ & $\begin{array}{l}\text { Mal- } \\
\text { Adjustment }\end{array}$ \\
\hline SELF ESTEEM - & Acute & $46.2 \%$ & $42.3 \%$ & $11.5 \%$ \\
\hline INFERIORITY & Chronic & $47.1 \%$ & $32.4 \%$ & $20.6 \%$ \\
\hline HAPPINESS & Acute & $34.6 \%$ & $26.9 \%$ & $38.5 \%$ \\
\hline DEPRESSION & Chronic & $41.2 \%$ & $20.6 \%$ & $38.2 \%$ \\
\hline CALMNESS - & Acute & $38.5 \%$ & $30.8 \%$ & $30.8 \%$ \\
\hline ANXIETY & Chronic & $35.3 \%$ & $44.1 \%$ & $20.6 \%$ \\
\hline
\end{tabular}




\begin{tabular}{|c|c|c|c|c|}
\hline \multirow{2}{*}{$\begin{array}{l}\text { NATURALITY } \\
\text { OBSESSIVENESS }\end{array}$} & Acute & $38.5 \%$ & $42.3 \%$ & $19.2 \%$ \\
\hline & Chronic & $29.4 \%$ & $23.5 \%$ & $47.1 \%$ \\
\hline \multirow{2}{*}{$\begin{array}{l}\text { INDEPENDENCE } \\
\text { DEPENDENCE }\end{array}$} & Acute & $30.8 \%$ & $50 \%$ & $19.2 \%$ \\
\hline & Chronic & $26.5 \%$ & $50 \%$ & $23.5 \%$ \\
\hline \multirow{2}{*}{$\begin{array}{l}\text { FEELINGS OF } \\
\text { BEING HEALTHY - } \\
\text { HYPOCHODRIASIS }\end{array}$} & Acute & $11.5 \%$ & $38.5 \%$ & $50 \%$ \\
\hline & Chronic & $23.5 \%$ & $26.5 \%$ & $50 \%$ \\
\hline \multirow{2}{*}{$\begin{array}{l}\text { INNOCENCE } \\
\text { GUILT }\end{array}$} & Acute & $57.7 \%$ & $34.6 \%$ & $7.7 \%$ \\
\hline & Chronic & $58.8 \%$ & $29.4 \%$ & $11.8 \%$ \\
\hline Overall ANDI & Acute & $19.2 \%$ & $69.2 \%$ & $11.5 \%$ \\
\hline
\end{tabular}

The overall Adjustment - Neuroticism findings indicate that a greater proportion of patients suffering from a chronic onset of their cardiac illness (29.4\%) were maladjusted as compared to those who had an acute onset of their heart illness (11.5\%). Thus, among cardiac patients, those with a chronic onset of their illness showed greater inclination towards maladjustment rather than those with an acute onset. When concerned about the domains of Self Esteem - Self Inferiority: Table indicates that on the dimension of Self Esteem - Self Inferiority, a greater proportion of patients suffering from a chronic onset of their cardiac illness (20.6\%) were maladjusted as compared to those who had an acute onset of their heart illness (11.5\%). Thus, those with a chronic onset of their illness showed greater inclination towards self inferiority. Table indicates that on the dimension of Happiness - Depression, a greater proportion of patients suffering from an acute onset of their cardiac illness (38.5\%) were maladjusted as compared to those who had a chronic onset of their heart illness (38.2\%) which is negligible as the difference is not significant. Table indicates that on the dimension of Calmness - Anxiety, a greater proportion of patients suffering from an acute onset of their cardiac illness (30.8\%) were maladjusted as compared to those who had a chronic onset of their heart illness (20.6\%). Thus, among cardiac patients, those with an acute onset of their illness showed grater inclination towards anxiety and apprehension rather than calmness. Table indicates that on the 
dimension of Nauturality - Obsessiveness, a greater proportion of patients suffering from a chronic onset of their cardiac illness $(47.1 \%)$ were maladjusted as compared to those who had an acute onset of their heart illness (19.2\%). Thus, among cardiac patients, those with a chronic onset of their illness showed greater inclination towards obsessiveness and orderliness rather than naturality and an easy going attitude. Table indicates that on the dimension of Independence - Dependence, a greater proportion of patients suffering from a chronic onset of their cardiac illness $(23.5 \%)$ were maladjusted as compared to those who had an acute onset of their heart illness (19.2\%). Thus, among cardiac patients, those with a chronic onset of their illness showed grater inclination towards dependence rather than independence and self dependence. Table indicates that, on the dimension of Feelings of Being Healthy Hypochondriasis, the proportion of patients suffering from an acute and chronic onset of their cardiac illness $(50 \%)$ were equally maladjusted. Thus it can be deduced that, among cardiac patients, those with an acute and chronic onset of their illness showed an equal inclination towards hypochondriasis rather than feelings of being healthy. Table indicates that on the dimension of Innocence - Guilt, a greater proportion of patients suffering from a chronic onset of their cardiac illness $(11.8 \%)$ were maladjusted as compared to those who had an acute onset of their heart illness $(7.7 \%)$. Thus it can be deduced that, among cardiac patients, those with a chronic onset of their illness showed grater inclination towards feelings of guilt rather than those of innocence.

\section{DISCUSSION:}

The study found that overall most of the chronic onset of their cardiac illness was maladjusted as compared to those who had an acute onset of heart illness. Likewise, when concerned about the domains of adjustment like: Self Esteem - Self Inferiority, Happiness - Depression, Nauturality - Obsessiveness, Independence - Dependence and Innocence - Guilt, chronic onset of cardiac illness patients have more maladjustment compare to acute onset of cardiac illness. This may be because chronic cardiac illness patient due to prolong and long lasting illness they have more stress, more inferiority, more depress, more obsess, more dependent and more guilty. Supportively, according to the study of Torpy, Lynm, and Glass (2007) found that chronic stress occurs over a longer time period. Stress hormones (catecholamines, including epinephrine, which is also known as adrenaline) have damaging effects if the heart is exposed to elevated catecholamine levels for a long time. Stress can cause increased oxygen demand on the body, spasm of the coronary (heart) blood vessels, and electrical instability in the heart's conduction system. Rustad, Stern, Hebert, and Musselman (2013) did a study on treatment of depression and found out that diagnose in patients with congestive heart failure, who often suffer from fatigue, insomnia, weight changes and other neurovegetative symptoms that overlap with those of depression. Pathophysiologic mechanisms connect depression and congestive heart failure. According to Hocaoglu, Yeloglu and Polat (2011) the relationship between psychological factors and cardiac disease required to be discussed. Because creation potential of the sudden death due to chronic cardiac diseases are more sensitive to the psychiatric disorders and 
development of any cardiac disease might start serious mental issues. These situations are the main subjects of psycho cardiology.

\section{SUMMARY AND CONCLUSION:}

The present study aimed at analyzing the pattern of adjustment-neuroticism and its dimensions among cardiac patients based on the onset of the cardiac disease (acute or chronic onset). The pattern of Adjustment - Neuroticism based on onset indicated a major percentage of acute onset patients showing normal status while among the chronic onset patients there were moderate amounts of patients in normal and well adjustment. A higher percentage of chronic patients indicated maladjustment as compared to the acute onset patients. Dimension wise percentages indicated a higher inclination towards hypochondriasis in both the groups and a higher percentage for obsessiveness in the chronic group. In conclusion, patients with chronic or severe illness react differently to the loss of functional abilities or the lifestyle modifications necessitated by their conditions.

\section{Limitations:}

1. The sample selection was convenience based, this was a critical limitation.

2. The samples of this study were cardiac patients familiar with the English language (those familiar with the local languages were not taken), which could be a limiting factor of the study.

3. Uneducated cardiac patients were not included as a part of the study due to the personal attention that would need to be provided to them. Consequently majority of the cardiac patients from the lower economic strata were left out.

\section{Suggestions and Further directions:}

1. Attempts can be made to cross validate the results of the present study by increasing the sample size and by including patients who are uneducated and unfamiliar with the English language, thus making the sample more representative of the universe of population being studied; this would aid in forming stronger generalizations.

2. Studying adjustment of cardiac patients immediately after a severe cardiac event could be an interesting area and phase to explore.

3. A personality profiling of cardiac patients could probably be an interesting area to explore, especially given the research that cardiac patients seem to possess a specific type of personality.

4. Future studies can focus on other variables important to understanding the psychological makeup of cardiac patients such as coping skills and strategies, social support, locus of control, emotional intelligence, and spiritual intelligence. 


\section{REFERENCES:}

1. Hocaoglu, C., Yeloglu, C.H., \& Polat, S. (2011). Cardiac Diseases and Anxiety Disorders, Anxiety and Related Disorders, Dr. Ã gnes Szirmai (Ed.), InTech, Retrieved from http://www.intechopen.com/books/anxiety-and-related-disorders/cardiac-diseases-and-anxietydisorders on 29/9/2014.

2. MeKonnen, H. B. (2011). Relationship between Agreeableness and Neuroticism and Cardiovascular Disease Among Older African American Men. Retrieved from http://gradworks.umi.com/34/40/3440011.html on 29/9/2014.

3.Rustad, J.K. , Stern, T.A., Hebert, K.A., \& Musselman, D.L. (2013).Diagnosis and Treatment of Depression in Patients With Congestive Heart Failure: A Review of the Literature. Retrieved from http://www.ncbi.nlm.nih.gov/pmc/articles/PMC3869617/ on 29/9/2014.

4. Singh, R. N. \& Bhargava, M. (1999). Manual for Adjustment Neuroticism Dimension Inventory (English Version). Agra: Nandini Enterprises.

5. Torpy, J.M., Lynm, C., Glass, \& R.M., (2007).Chronic Stress and the Heart. The Journal of American Medical Association, 298(14). Retrieved from http://jama.jamanetwork.com/article.aspx?articleid=209139 on 29/9/2014. 